\title{
Antioxidant Activity, and $\alpha$-Glucosidase, $\alpha$-Amylase and Lipase Inhibitory Activity of Polyphenols in Flesh, Peel, Core and Seed from Mini Apple
}

\author{
Zhaohong $\mathrm{Ci}^{1{ }^{1,2}}{ }^{\text {, Kazuto Kikuchi }}{ }^{1}$, Aoi Hatsuzawa ${ }^{1}$, Arisa Nakai ${ }^{1}$, Chengyu Jiang ${ }^{1,2}$, \\ Atsushi Itadani ${ }^{2,3}$, Michiyuki Kojima ${ }^{2,3, *}$ \\ ${ }^{1}$ Department of Food Science, Obihiro University of Agriculture and Veterinary Medicine, 11, \\ Nishi-2-sen, Inada-machi, Obihiro, Hokkaido 080-8555, Japan \\ ${ }^{2}$ United Graduate School of Agricultural Sciences, Iwate University, 3-18-8, Ueda, Morioka, Iwate 020-8550, Japan \\ ${ }^{3}$ Department of Human Sciences, Obihiro University of Agriculture and Veterinary Medicine, 11, \\ Nishi-2-sen, Inada-machi, Obihiro, Hokkaido 080-8555, Japan \\ *Corresponding author: kojima@obihiro.ac.jp
}

Received September 17, 2018; Revised October 21, 2018; Accepted November 15, 2018

\begin{abstract}
Dietary inhibitors of fats and carbohydrates degrading digestive enzymes can reduce obesity and type 2 diabetes. In this study, we investigated and compared polyphenol content, DPPH radical scavenging activity, and inhibitory activity on digestive enzymes, including $\alpha$-glucosidase, $\alpha$-amylase and lipase in flesh, peel, core and seed from mini apple (Malu domestica cv. 'Alps Otome'). Polyphenol content was significantly higher in peel and seed extracts than in flesh and core extracts. As comparing with flesh, peel polyphenols exhibited stronger DPPH radical scavenging activity, and $\alpha$-amylase and lipase inhibitory activity. Oligomeric polyphenols (Fra.II) were the main polyphenols in seed extracts, which exhibited significantly strong DPPH radical scavenging activity and inhibitory activity on digestive enzymes. However, monomeric polyphenols (Fra.I) were the main polyphenols in core extracts, which exhibited weak inhibitory activity on digestive enzymes than the other parts. Moreover, Fra.III of seed and peel extracts had the highest inhibitory activity on $\alpha$-glucosidase, followed by Fra.II and Fra.I, respectively. It indicated that more highly polymerized polyphenols from peel and seed of mini apple showed more potent inhibitory activities on $\alpha$-glucosidase. All of the observations suggested that mini apples possess useful properties. Particularly, it has potential applications for the treatment of diabetes and obesity.
\end{abstract}

Keywords: mini apple, polyphenol, DPPH radical scavenging activity, $\alpha$-glucosidase, $\alpha$-amylase, lipase

Cite This Article: Zhaohong Ci, Kazuto Kikuchi, Aoi Hatsuzawa, Arisa Nakai, Chengyu Jiang, Atsushi Itadani, and Michiyuki Kojima, "Antioxidant Activity, and $\alpha$-Glucosidase, $\alpha$-Amylase and Lipase Inhibitory Activity of Polyphenols in Flesh, Peel, Core and Seed from Mini Apple." American Journal of Food Science and Technology, vol. 6, no. 6 (2018): 258-262. doi: 10.12691/ajfst-6-6-5.

\section{Introduction}

An imbalance between energy intake and expenditure may result in the abnormal growth of adipose tissue, thereby leading to obesity [1]. According to the World Health Organization (WHO), limiting energy intake from total fats and sugars could suppress overweight and obesity as well as their related diseases, engaging in regular physical activity, and increasing consumption of fruits, vegetables, legumes, whole grains, and nuts. Dietary intervention seems to be an effective option for treatment of obesity and type 2 diabetes. Inhibition of dietary fat and sugar absorption from the intestine seems to be an effective way to prevent obesity and type 2 diabetes. $\alpha$-Glucosidase is a membrane-bound enzyme located in the epithelium of the small intestine, and it catalyzes the cleavage of glycosidic bonds and releases of glucose from disaccharides and oligosaccharides [2]. Pancreatic $\alpha$-amylase is an endoglucosidase that is delivered into the intestinal lumen as a constituent of pancreatic juices and catalyzes the hydrolysis of starch to maltose and maltotriose [2]. Pancreatic lipase is a key enzyme for fat digestion, blocking fat decomposition and absorption by its inhibition is an effective approach for preventing obesity. Some researchers have reported that many kinds of plants had potential $\alpha$-glucosidase, $\alpha$-amylase, and lipase inhibitory activities $[3,4,5,6,7]$.

Apple is one of the most popular fruits, and contains many types of polyphenols consisting of procyanidin, epicatechin, catechin, p-coumaroyl quinic acid, chlorogenic acid, rutin [8]. Apple polyphenols possess some bioactive activities, such as antioxidant activity and anti-allergic effect [9], anti-cancer effect [10], and anti-aging effect [11]. Mini apple (Malu domestica cv. 'Alps Otome') is one of the Japanese apple cultivars and tastes sweet in flavor. However, due to the diminutive size, mini apple is 
not widely cultivated. In the present study, we investigated antioxidant activity, and $\alpha$-glucosidase, $\alpha$-amylase and lipase inhibitory activity of polyphenols in flesh, peel, core and seed of mini apple.

\section{Materials and Methods}

\subsection{Reagents}

All the reagents and chemicals were purchased from Wako Pure Chemical Industries, Ltd. (Osaka, Japan), unless otherwise stated. Diaion HP-20 columns and Sephadex LH-20 columns for chromatography were obtained from the Mitsubishi Chemical Corporation (Tokyo, Japan) and GE Healthcare Bio-Sciences AB (Uppsala, Sweden), respectively.

\subsection{Samples}

Mini apple was at their commercial ripening stage and obtained from supermarket (Obihiro, Japan). The weight of a fresh mini apple was $23.1 \pm 1.3 \mathrm{~g}$. Food Standards Australia New Zealand (FSANZ) [12] reported the weight of a fresh Fuji apple ranged from $145 \mathrm{~g}$ to $180 \mathrm{~g}$. Moreover, the weight of flesh, peel, core and seed for a fresh mini apple was $17.5 \pm 3 \mathrm{~g}, 2.7 \pm 0.4 \mathrm{~g}, 2.5 \pm 0.5 \mathrm{~g}$, and $0.25 \pm 0.1 \mathrm{~g}$, respectively.

\subsection{Extract Preparation and Fractionation}

The fresh mini apple was manually separated into flesh, peel, core and seed. The flesh, peel and core were cut into pieces, and homogenized using a Teflon homogenizer, respectively. The seed was crushed with mortar. The crushed flesh, peel, core and seed were added with $20 \mathrm{~mL}$ of $80 \%$ ethanol and treated with ultrasound for $30 \mathrm{~min}$, respectively. The mixture was centrifuged at $1,006 \times g$ for $10 \mathrm{~min}$ to obtain the supernatant. The same extraction process was repeated twice more. The residues were subjected to another three rounds times of extraction with $70 \%$ acetone-water, and the supernatant was obtained. Then, the supernatant was mixed, concentrated by rotary evaporation in a vacuum at $35^{\circ} \mathrm{C}$, and purified by chromatography through a Diaion HP-20 column. The columns were washed with distilled water and then eluted with methanol. The methanol solution was concentrated by rotary evaporation in a vacuum at $35^{\circ} \mathrm{C}$ and dissolved in $2 \mathrm{~mL}$ of methanol for the experiment. Part of the concentrate was dissolved in ethanol and fractionated by Sephadex LH-20 column chromatography. The column was successively eluted with ethanol, methanol, and $60 \%$ acetone to collect fraction I (Fra.I), fraction II (Fra.II), and fraction III (Fra.III), respectively.

\subsection{Quantification of Polyphenols}

Polyphenols were quantified using the Folin-Ciocalteu method [13]. The methanol fraction (after HP-20 column; $100 \mu \mathrm{L}$ ) was treated with $300 \mu \mathrm{L}$ of distilled water, $400 \mu \mathrm{L}$ of Folin-Ciocalteu reagent, and $400 \mu \mathrm{L}$ of a $10 \%$ $\mathrm{Na}_{2} \mathrm{CO}_{3}$ solution. The mixture was prepared in triplicate, incubated at $30{ }^{\circ} \mathrm{C}$ for $30 \mathrm{~min}$, and centrifuged at $1,006 \times \mathrm{g}$ for $10 \mathrm{~min}$. The absorbance of the mixed supernatant was measured at $760 \mathrm{~nm}$. The polyphenol content is expressed in milligrams of catechin equivalents per gram of fresh materials.

\subsection{Estimation of 2,2-diphenyl-1-picrylhydrazyl (DPPH) Radical Scavenging Activity}

DPPH radical scavenging activity was evaluated by the method described by Brand-Williams et al. [14] with some modifications. A $50-\mu \mathrm{L}$ aliquot of the methanol fraction (after HP-20 column) was mixed with $100 \mu \mathrm{L}$ of ethanol, and the mixture was supplemented with $150 \mu \mathrm{L}$ of $0.5 \mathrm{mM}$ DPPH solution in ethanol. The absorbance of the mixture was measured using a microplate reader at $517 \mathrm{~nm}$. The DPPH radical scavenging activity was expressed in micromoles of trolox equivalents per gram of fresh materials.

\section{6. $\alpha$-Glucosidase and $\alpha$-Amylase Inhibitory Activity}

$\alpha$-Glucosidase and $\alpha$-amylase inhibitory activity were analyzed following the methods of Matsumoto et al. [15] with modifications. In total, $0.8 \mathrm{~mL}$ of enzyme reaction solution $(50 \mu \mathrm{L}$ of $0.4 \%$ sucrose for $\alpha$-glucosidase inhibitory activity and $0.5 \%$ starch for $\alpha$-amylase inhibitory activity, $625 \mu \mathrm{L}$ of $0.1 \mathrm{~mol} / \mathrm{L}$ sodium phosphate buffer ( $\mathrm{pH} 6.8$ ), and $125 \mu \mathrm{L}$ of $1 \% \mathrm{NaCl}$ ) was pre-incubated at $37^{\circ} \mathrm{C}$ for $30 \mathrm{~min}$. The methanol fraction (after HP-20 column) was concentrated by rotary evaporation in a vacuum at $35^{\circ} \mathrm{C}$ and dissolved in distilled water. Distilled water fraction was added to $0.1 \mathrm{U} / \mathrm{mL}$ yeast $\alpha$-glucosidase (EC3.2.1.20; Oriental Yeast Co., Ltd., Tokyo, Japan) solution and porcine pancreatic $\alpha$-amylase (EC3.2.1.1; Sigma-aldrich Inc. Co., LLC, Steinheim, Germany) solution at $37^{\circ} \mathrm{C}$ for $10 \mathrm{~min}$. After pre-incubation, $200 \mu \mathrm{L}$ of the mixture (polyphenol extract and $\alpha$-glucosidase, $\alpha$-amylase) was added to the enzyme reaction solution and incubated at $37^{\circ} \mathrm{C}$ for $30 \mathrm{~min}$. The reaction was terminated by adding $125 \mathrm{~mL}$ of $2 \mathrm{M} \mathrm{NaOH}$ and $1 \%$ dinitrosalicylic acid in boiling water for $10 \mathrm{~min}$. After incubation, the mixture was analyzed at $540 \mathrm{~nm}$ at $25^{\circ} \mathrm{C}$. Enzyme inhibitory reactions for all polyphenol extract concentrations were replicated three times. The enzyme inhibitory activity is expressed as the percent inhibition. The concentration of inhibitors required for the inhibition of $50 \%$ of the enzyme activity under the assay conditions was defined as the $\mathrm{IC}_{50}$ value.

The inhibitory kinetics of $\alpha$-glucosidase by the polyphenol extract were determined by the Lineweaver-Burk equation. Sucrose was used as the substrate in the concentration range of 3.3-20.0 mM. The enzyme activity was measured at 0 and $0.2 \mu \mathrm{g} / \mathrm{mL}$ polyphenols.

\subsection{Lipase Inhibitory Activity}

The assay for determining pancreatic lipase activity in vitro was carried out with a slightly modified version of the protocol described in Han et al. [16]. Briefly, $30 \mu \mathrm{L}$ of $3 \mathrm{mg} / \mathrm{mL}$ porcine pancreatic lipase (Sigma-aldrich Inc. Co., LLC, Steinheim, Germany) solution and $0.45 \mathrm{~mL}$ of various concentrations of sample solution were pre-incubated 
for $10 \mathrm{~min}$ at $37^{\circ} \mathrm{C}$. After pre-incubation, a substrate solution containing glycerol triolein $(80 \mathrm{mg})$, phosphatidylcholine $(10 \mathrm{mg})$ and cholic acid $(5 \mathrm{mg})$ in $9 \mathrm{~mL}$ of $0.1 \mathrm{M} \mathrm{N}$-(tris (hydroxymethyl) methyl)-2-aminoethanesulfonic acid buffer (pH 7.0) was added and incubated for $30 \mathrm{~min}$ at $37^{\circ} \mathrm{C}$. Afterward, $2.5 \mathrm{~mL}$ of $1 \mathrm{M}$ copper reagent and $5 \mathrm{~mL}$ chloroform were added to the reaction mixture, which was then centrifuged at $1,006 \times g$ for $10 \mathrm{~min}$. The upper, aqueous phase was removed, whereas sodium diethyldithiocarbamate was added to the lower, free fatty acid-containing chloroform phase. The absorbance was measured at $440 \mathrm{~nm}$ and lipid concentrations were calculated using linoleic acid as a standard equivalent. Lipase inhibitory activity (\%) was calculated from the following formula:

$$
\text { Lipase inhib. activity }(\%)=\left(1-\frac{F F A_{\text {sample }}}{F F A_{\text {control }}}\right) \times 100 \%
$$

where $F F A_{\text {sample }}$ and $F F A_{\text {control }}$ are the quantities of free lipids in the sample and the control, respectively. The pancreatic lipase inhibitory activity was expressed with $\mathrm{IC}_{50}$ value.

\subsection{Statistical Analysis}

Values are presented as the means \pm standard deviations. Statistical significance was evaluated by analysis of variance (ANOVA) and least significant difference (LSD) tests (SAS Enterprise Guide 5.1 system, Cary, NC, USA). Differences were considered significant at $p<0.05$.

\section{Results and Discussion}

\subsection{Polyphenol Content}

Polyphenol contents in flesh, peel, core and seed extracts of mini apple is presented in Table 1. The highest polyphenol content $(6.5 \pm 0.2 \mathrm{mg} / \mathrm{g})$ was in peel extracts, and the lowest polyphenol content $(1.3 \pm 0.1 \mathrm{mg} / \mathrm{g})$ was in flesh extracts $(p<0.05)$. This agree with the research reporting concentration of polyphenols in the peel of apple. Polyphenol content was much higher than in the flesh [17]. We also found peel of European pears and Japanese pears that peel had higher polyphenol content than those of flesh [18]. Moreover, Leontowicz et al. [17] reported that polyphenol content was $1.07 \pm 0.1 \mathrm{mg} / \mathrm{g}$ in apple peel and $0.62 \pm 0.1 \mathrm{mg} / \mathrm{g}$ in apple flesh. As comparing with this research, mini apple peel and flesh then exhibited higher polyphenol content.

Table 1. Polyphenols and DPPH radical scavenging activity in flesh, peel, core and seed

\begin{tabular}{ccc}
\hline Parts & $\begin{array}{c}\text { Polyphenols * } \\
(\mathrm{mg} / \mathrm{g})\end{array}$ & $\begin{array}{c}\text { DPPH radical scavenging activity * * } \\
(\mu \mathrm{mol} / \mathrm{g})\end{array}$ \\
\hline Flesh & $1.3^{\mathrm{d}} \pm 0.1$ & $3.6^{\mathrm{c}} \pm 0.1$ \\
Peel & $6.5^{\mathrm{a}} \pm 0.2$ & $12.3^{\mathrm{a}} \pm 0.1$ \\
Core & $1.6^{\mathrm{c}} \pm 0.0$ & $4.9^{\mathrm{b}} \pm 0.2$ \\
Seed & $6.1^{\mathrm{b}} \pm 0.1$ & $12.3^{\mathrm{a}} \pm 0.4$ \\
\hline
\end{tabular}

*expressed as mg of catechin equivalents per gram of fresh materials. $* *$ expressed as $\mu \mathrm{mol}$ trolox equivalents per gram of fresh materials. Values are means \pm standard deviations. Different superscript letters indicate significant differences $(p<0.05)$.

\subsection{DPPH Radical Scavenging Activity, $\alpha$-Glucosidase, $\alpha$-Amylase, and Lipase Inhibitory Activity}

Antioxidants could react with the stable free radical DPPH (deep violet color) and convert it to 1,1-diphenyl-2-picryl hydrazine, resulting in dis-coloration. Mini apple peel and seed extracts had significantly higher DPPH radical scavenging activity, followed with core and flesh extracts $(p<0.05)$ (Table 1). The results agreement with peel extracts had higher total soluble phenolic content and antioxidant capacity than flesh extracts [19]. We found a positive correlation between polyphenol content and DPPH radical scavenging activity, and its correlation coefficient $\left(\mathrm{r}^{2}\right)$ is 0.99 . Many studies have demonstrated that polyphenols from fruits possessed strong antioxidant activity [20,21].

We next analyzed the inhibitory activities of the polyphenol extracts against $\alpha$-glucosidase, $\alpha$-amylase and lipase. Polyphenol extracts from different parts of mini apple showed inhibitory activity on $\alpha$-glucosidase (Table 2 ). The $\mathrm{IC}_{50}$ value of seed polyphenol extracts was significantly lower than those of flesh, peel and core. It indicated that seed polyphenols exhibited the strongest $\alpha$-glucosidase inhibitory activity. No significant difference was found between flesh and peel polyphenol extracts on $\alpha$-glucosidase. Core polyphenol extracts had the lowest $\alpha$-glucosidase inhibitory activity among all different parts. Moreover, we performed an enzyme kinetic study of $\alpha$-glucosidase inhibitory activity in Figure 1. It showed a Lineweaver-Burk plot of the $\alpha$-glucosidase inhibitory activity of seed polyphenol extracts at 0 and $0.2 \mu \mathrm{g} / \mathrm{mL}$, with different concentrations of sucrose (3.3-20.0 mM). Polyphenols from seed showed non-competitive inhibition on $\alpha$-glucosidase. The maximum velocity $\left(V_{\max }\right)$ was $0.7 \mathrm{mmol} / \mathrm{min}$ and the Michaelis-Menten constant $\left(K_{\mathrm{m}}\right)$ was $79.80 \mathrm{mM}$ for sucrose. Polyphenols from flesh, peel and core also showed non-competitive inhibition on $\alpha$-glucosidase. The maximum velocities $\left(V_{\max }\right)$ of flesh, peel and core were $1.8,1.7$ and $0.2 \mathrm{mmol} / \mathrm{min}$, respectively and the Michaelis-Menten constant $\left(K_{\mathrm{m}}\right)$ was $91.0,133.9$ and 36.1 $\mathrm{mM}$ for sucrose, respectively.

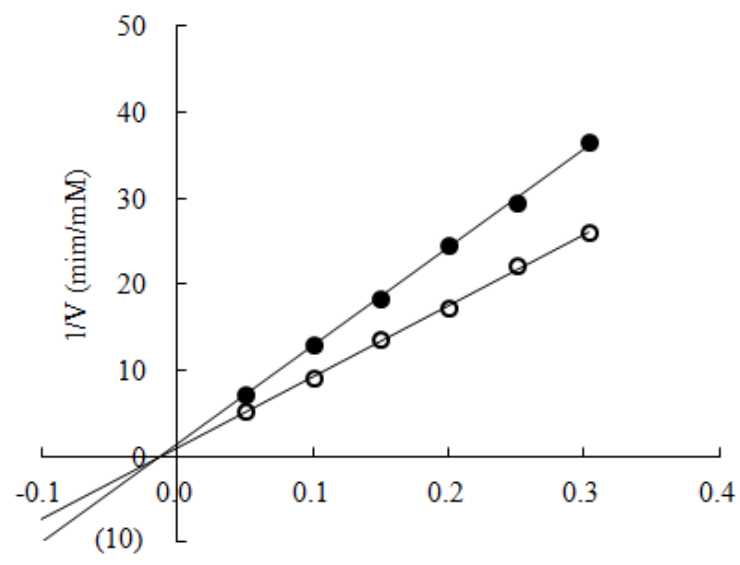

$1 / \mathrm{S}(\mathrm{mM})$

Figure 1. Non-competitive inhibition of polyphenols extracts on $\alpha$-glucosidase for seed of mini apple. Symbols: $\circ, 0 \mu \mathrm{g} / \mathrm{mL} ; \bullet, 0.2 \mu \mathrm{g} / \mathrm{mL}$

Polyphenols from different parts of mini apple showed inhibitory effects on $\alpha$-amylase (Table 2). Sun et al. [22] reported that thinned young apple had $\alpha$-amylase 
inhibitory activity with $\mathrm{IC}_{50}$ value was $177 \mu \mathrm{g} / \mathrm{mL}$. In our study, seed polyphenol extracts exhibited extremely strong $\alpha$-amylase inhibitory activity $\left(\mathrm{IC}_{50}\right.$ value of $\left.1.1 \mu \mathrm{g} / \mathrm{mL}\right)$, comparing with the other different parts. Peel polyphenol extracts exhibited greater inhibitory activity than flesh and core against $\alpha$-amylase. Apple peel extracts showed higher $\alpha$-glucosidase inhibitory activity along with lower $\alpha$-amylase inhibitory activity, comparing with flesh extracts [19]. However, in our research, there was no significant difference between flesh and peel polyphenol extracts on $\alpha$-glucosidase, and peel polyphenol extracts had stronger inhibitory activity on $\alpha$-amylase comparing with flesh. For flesh, peel and core polyphenols, $\mathrm{IC}_{50}$ values were lower on $\alpha$-glucosidase inhibitory activity than on $\alpha$-amylase inhibitory activity. It indicated that the inhibitory activity on $\alpha$-glucosidase was stronger than on $\alpha$-amylase. In addition, seed polyphenols exhibited strong inhibitory activity both on $\alpha$-amylase and $\alpha$-glucosidase. We considered that polyphenol composition may affected the strength of inhibitory activities on different digestive enzymes. Chlorogenic acid, procyanidin $\mathrm{B}_{2}$, epicatechin were found in flesh, peel and core of apple [23]. However, the polyphenol composition of seed almost has not reported.

Table 2. $\alpha$-Glucosidase, $\alpha$-amylase, and lipase inhibitory activity of polyphenol extracts in flesh, peel, core and seed

\begin{tabular}{cccc}
\hline \multirow{2}{*}{ Parts } & \multicolumn{3}{c}{ Enzyme inhibitory activities $\mathrm{IC}_{50}(\mu \mathrm{g} / \mathrm{mL})$} \\
\cline { 2 - 4 } & $\alpha$-Glucosidase & $\alpha$-Amylase & Lipase \\
\hline Flesh & $2.7^{\mathrm{b}} \pm 0.1$ & $17.6^{\mathrm{b}} \pm 0.6$ & $8.3^{\mathrm{b}} \pm 0.2$ \\
Peel & $2.6^{\mathrm{b}} \pm 0.1$ & $10.7^{\mathrm{c}} \pm 0.2$ & $6.2^{\mathrm{c}} \pm 0.2$ \\
Core & $3.9^{\mathrm{a}} \pm 0.1$ & $58.2^{\mathrm{a}} \pm 0.8$ & $8.9^{\mathrm{a}} \pm 0.3$ \\
Seed & $1.0^{\mathrm{c}} \pm 0.1$ & $1.1^{\mathrm{d}} \pm 0.1$ & $3.8^{\mathrm{d}} \pm 0.1$ \\
\hline
\end{tabular}

Values are means \pm standard deviations. Different superscript letters indicate significant differences $(p<0.05)$.

Pancreatic lipase is the most important enzyme responsible for digestion of dietary fat, so its inhibition can lead to beneficial effects on overweight and obesity. Polyphenols from different parts of mini apple showed the inhibitory activity on lipase, and the $\mathrm{IC}_{50}$ values ranged from 3.8 to $8.9 \mu \mathrm{g} / \mathrm{mL}$. Polyphenols from seed exhibited stronger lipase inhibitory activity, followed by peel, flesh and core. Some studies also demonstrated that lipase activity was effectively inhibited by phenolic-rich extracts of fruits including apple $[2,24]$.

\subsection{Polyphenol Fractions}

We performed Sephadex LH-20 column chromatography to obtain three polyphenol fractions, i.e., Fra.I, Fra.II, and Fra.III, respectively from different parts extracts of mini apple. According to Saito et al. [25], Fra.I contains monomeric polyphenols, Fra.II contains oligomeric polyphenols, and Fra.III contains polymeric polyphenols. Oligomeric and polymeric polyphenols are considered as proanthocyanidins. Proanthocyanidins belong to flavonoids and oligomers or polymers of flavan-3-ols. For flesh and peel, the percentage of monomeric and oligomeric polyphenols was $40-47 \%$, respectively, and the percentage of Fra.III was less than $17 \%$. The main polyphenols was monomeric polyphenols $(67.7 \%)$ in core, in contrast, oligomeric polyphenols $(60.8 \%)$ was the main polyphenols in seed (Figure 2).

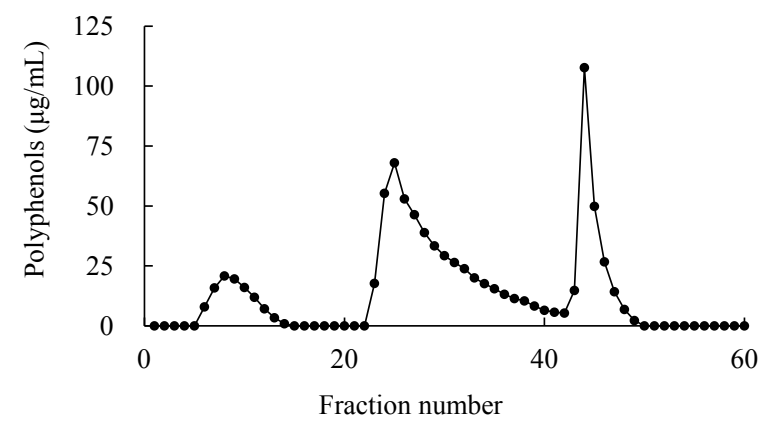

Figure 2. Seed polyphenol extracts were applied to LH-20 column. The polyphenol fractions obtained by Diaion HP-20 column chromatography were applied to Sephadex LH-20 column chromatography and eluted with ethanol, fraction number 1-20, fraction I; methanol, fraction number 21-40, fraction II; and 60\% acetone, fraction number $41-60$, fraction III

Moreover, we investigated $\alpha$-glucosidase inhibitory activity of Fra.I, Fra.II, and Fra.III in seed and peel (Table 3). The highest inhibitory activity was found in Fra.III of seed and peel, followed by Fra.II and Fra.I. It indicated that more highly polymerized polyphenols exhibited more potent inhibitory activities on $\alpha$-glucosidase. Consistent with this, we also observed that oligomeric and polymeric polyphenols exhibited stronger $\alpha$-glucosidase inhibitory activity than monomeric polyphenols in pears and scarlet runner beans $[18,21]$. These results may be explain why seed polyphenols had the strongest inhibitory activity than the other parts on digestive enzymes. That is the percentage of oligomeric polyphenols were more in seed, which exhibited the stronger inhibitory activity on $\alpha$ glucosidase, $\alpha$-amylase and lipase. However, the percentage of monomeric polyphenols was more in core, which exhibited lower inhibitory activity on these digestive enzymes. Oligomeric polyphenols seem also to be more potent inhibitory activities than monomeric polyphenol on $\alpha$-amylase and lipase. Lu et al. [26] reported that oligomeric proanthocyanidins from okra inhibited $\alpha$-amylase and $\alpha$-glucosidase inhibitory activity.

Table 3. $\alpha$-Glucosidase inhibitory activity of polyphenols in Fra.I, Fra.II and Fra.III after Sephadex LH-20 from peel and seed

$$
\alpha \text {-Glucosidase inhibitory activity }
$$

\begin{tabular}{ccc} 
& \multicolumn{2}{c}{$\mathrm{IC}_{50}(\mu \mathrm{g} / \mathrm{mL})$} \\
Fractions & Seed & Peel \\
\hline Fra.I & $11.8^{\mathrm{a}} \pm 0.2$ & $19.9^{\mathrm{a}} \pm 0.3$ \\
Fra.II & $1.0^{\mathrm{b}} \pm 0.1$ & $1.9^{\mathrm{b}} \pm 0.1$ \\
Fra.III & $0.6^{\mathrm{c}} \pm 0.1$ & $0.8^{\mathrm{c}} \pm 0.1$ \\
\hline
\end{tabular}

Values are means \pm standard deviations. Different superscript letters indicate significant differences $(p<0.05)$.

Abbreviations: Fra.I, fraction I; Fra.II, fraction II, Fra.III, fraction III.

\section{Conclusions}

Mini apple contained abundant polyphenols and antioxidant activity, especially in peel and seed. Moreover, polyphenol extracts in all different parts of mini apple inhibited the activities of digestive enzymes, including $\alpha$-glucosidase, 
$\alpha$-amylase and lipase. These observations could provide the important information for the use of mini apple, which may serve as a source for development of nutraceuticals with antioxidant, anti-diabetes and anti-obesity.

\section{Acknowledgements}

We acknowledge the financial support provided by the Obihiro University of Agriculture and Veterinary Medicine, as well as Iwate University.

\section{Statement of Competing Interests}

The authors have no competing interests.

\section{References}

[1] Spiegelman, B.M., Flier, J.S, "Obesity and the regulation of energy balance," Cell, 104 (4). 531-543. Feb.2001.

[2] Podsędek, A., Majewska, I., Redzynia, M., Sosnowska, D., Koziołkiewicz, M, "In vitro inhibitory effect on digestive enzymes and antioxidant potential of commonly consumed fruits," Journal of Agricultural and Food Chemistry, 62. 4610-4617. May.2014.

[3] Yun, J. W, "Possible anti-obesity therapeutics from nature--a review," Phytochemistry, 71. 1625-1641. Oct.2010.

[4] Kumar, S., Narwal, S., Kumar, V., Prakash, O, " $\alpha$-Glucosidase inhibitors from plants: A natural approach to treat diabetes," Pharmacognosy, 5. 19-29. Jan.2011.

[5] De Sales, P. M., Souza, P. M., Simeoni, L. A., Silveira, D, “ $\alpha-$ Amylase inhibitors: a review of raw material and isolated compounds from plant source," Journal of Pharmacy \& Pharmaceutical Sciences, 15. 141-183. Jan.2012.

[6] Roh, C., Jung, U, "Screening of crude plant extracts with antiobesity activity," International Journal of Molecular Sciences, 13. 1710-1719. Feb.2012.

[7] Ci, Z.H., Jiang, C.Y., Feng, S., Wu, S., Cui, Y., Sasaki, Y., Kojima, M, "Anti-Obesity Effect of Proanthocyanidins from the Coat of Scarlet Runner Beans on High-Fat Diet-Fed Mice," Journal of Food and Nutrition Research, 6 (2). 103-109. Feb.2018a.

[8] Kao, Y.L., Kuo, Y.M., Lee, Y.R., Yang, S.F., Chen, W.R., Lee, H.J., "Apple polyphenol induces cell apoptosis, cell cycle arrest at G2/M phase, and mitotic catastrophe in human bladder transitional carcinoma cells," Journal of Functional Foods, 14. 384-394. Apr.2015.

[9] Akiyama, H., Sakushima, J., Taniuchi, S., Kanda, T., Yanagida, A., Kojima, T., Teshima, R., Kobayashi, Y., Goda, Y., Toyoda, M, "Antiallergic effect of apple polyphenols on the allergic model mouse," Biological and Pharmaceutical Bulletin, 23 (11). 1370-3. Nov.2000.

[10] Miura, T., Chiba, M., Kasai, K., Nozaka, H., Nakamura, T., Shoji, T., Kanda, T., Ohtake, Y., Sato, T, "Apple procyanidins induce tumor cell apoptosis through mitochondrial pathway activation of caspase-3," Carcinogenesis, 29 (3). 585-93. Mar.2008.

[11] Sunagawa, T., Shimizu, T., Kanda, M., Tagashira, M., Sami, M., Shirasawa, T, "Procyanidins from apples (Malus pumila Mill.) extend the lifespan of Caenorhabditis elegans," Journal of
Medicinal Plant and Natural Product Research, 77 (2). 122-127. Jan.2011.

[12] "Fruits and Vegetable Measures Program" Food standards Australia New Zealand (FSANZ), [Online]

Available:http://www.foodstandards.gov.au/science/monitoringnut rients/ausnut/foodmeasures/Pages/-Fruits-and-vegetablemeasures-program---data-table.aspx. (Accessed Oct.3, 2018)

[13] Miyashita, J., Nishi S., Saito Y., Koaze, H., Hironaka, K. and Kojima, M, "Annual variations in the anthocyanin contents of blueberry fruit grown in Hokkaido," Research Bulletin of Obihiro University of Agriculture and Veterinary Medicine, 28. 35-40. Oct.2007.

[14] Brand-Williams, W., Cuvelier, M.E., Berset, C, "Use of a free radical method to evaluate antioxidant activity," LebensmittelWissenschaft und Technologie, 28. 25-30. Jun.1994.

[15] Matsumoto, N., Ishigaki, A., Iwashina, H., Hara, Y, "Reduction of blood glucose levels by tea catechin," Bioscience, Biotechnology, Biochemistry, 57. 525-527. Jun.1993.

[16] Han, L.K., Xu, B.J., Kimura, Y., Zheng, Y., Okuda, H, "Platycodi radix affects lipid metabolism in mice with high fat diet-induced obesity," Nutrient Metabolism, 130 (11). 2760-2764. Nov.2000.

[17] Leontowicz, M., Gorinstein, S., Leontowicz, H., Krzeminski, R., Lojek, A., Katrich E., Cíz M., Martin-Belloso, O., Soliva-Fortuny, R., Haruenkit, R., Trakhtenberg, S, “Apple and pear peel and pulp and their influence on plasma lipids and antioxidant potentials in rats fed cholesterol-containing diets," Journal of Agricultural and Food Chemistry, 51(19). 5780-5. Sep.2003.

[18] Ci, Z.H, Kojima, M, "Antioxidant and $\alpha$-glucosidase inhibitory activity of polyphenols in peel and core from five different pear varieties" Journal of Food and Nutrition Research, 6 (9). 546-550. Sep.2018b.

[19] Barbosa, A. C. L., Pinto, M. da, S., Sarkar, D., Ankolekar, C., Greene, D., Shetty, K, "Varietal influences on antihyperglycemia properties of freshly harvested apples using in vitro assay models," Journal of Medicinal Food, 13. 1313-1323. Dec.2010.

[20] Saidani F., Giménez R., Aubert C., Chalot G., Betrán J.A., Gogorcena Y, "Phenolic, sugar and acid profiles and the antioxidant composition in the peel and pulp of peach fruits," Journal of Food Composition and Analysis, 62. 126-133. Sep.2017.

[21] Ci, Z.H, Jiang, C.Y., Kojima, M, "Suppressive effect of polyphenols from the seed coat of scarlet runner beans on blood glucose levels," Journal of Food and Nutrition Research, 6 (3). 182-186. Mar.2018c.

[22] Sun, L., Chen, W., Meng, Y., Yang, X., Yuan, L., Guo, Y, "Interactions between polyphenols in thinned young apples and porcine pancreatic $\alpha$-amylase: Inhibition, detailed kinetics and fluorescence quenching," Food Chemistry, 208. 51-60. Oct.2016.

[23] Shoji Toshihiko, "The Science of Apple fruit polyphenols The Science of Apple fruit polyphenols," Food and Packaging, 54 (3). 143-149. Mar.2013.

[24] McDougall, G. J., Kulkarni, N. N., Stewart, D, "Berry polyphenols inhibit pancreatic lipase activity in vitro," Food Chemistry, 115. 193-199. Jul.2009.

[25] Saito, Y., Nishi, S., Koaze, H., Hironaka, K., Kojima, M, "Antioxidant and inhibitory activity on $\alpha$-amylase and $\alpha$ glucosidase in legume polyphenols," Nippon Shokuhin Kagaku Kogaku Kaishi, 54 (12). 563-567. Jan.2007.

[26] Lu, Y.Y., Demleitner, M. F., Song, L.X., Rychlik, M., Huang, D.J., "Oligomeric proanthocyanidins are the active compounds in Abelmoschus esculentus Moench for its $\alpha$-amylase and $\alpha$ glucosidase inhibition activity," Journal of Functional Food, 20. 463-471. Jan.2016. 